\title{
Value of Influenza Vaccines in Cancer Patients during the Coronavirus (COVID-19) Pandemic
}

\author{
Mozafar Aznab ${ }^{1}$, Narges Eskandari Roozbahani ${ }^{1}$, and Homa Moazen ${ }^{2}$ \\ ${ }^{1}$ Kermanshah University of Medical Sciences \\ ${ }^{2}$ Affiliation not available
}

November 27, 2020

\begin{abstract}
Background \& aims: According to the recommendation of the Centers for Disease Control and Prevention (CDC), getting Influenza Vaccines during the Coronavirus (COVID-19) pandemics is especially important for people with certain underlying medical conditions, like cancer. Due to the similarities between the symptoms of influenza and Covid-19, receiving the flu vaccine in suspicious cases can be helpful because it will make it easier to request a medical test and diagnosis. In this crosssectional descriptive study, the value of influenza vaccination in the cancer population was investigated. Subjects and Methods: All cancer patients who were referred to our clinic and had eligibility to receive the flu vaccine were included in our study for following up clinical signs every week for one month. All patients who were vaccinated from October 1 to 15, 2020, were investigated. The most side effects that were followed were fever, runny nose, bone pain, life-threatening, or persistent adverse effects. Results: From a total of 289 patients [median age: 52 years (range 18-79), 112 (38.9\%) males and 176 (61.1\%) female] with different types of cancers, only two patients had an adverse effect of vaccination (including bone pain, runny nose, and fatigue), and one had Covid-19 ten days after vaccination. The rest of the patients did not show any side effects due to flu vaccination after one month of follow-up.
\end{abstract}

\section{Hosted file}

$\mathrm{flu}$ vaccination and cancer patients.pdf available at https://authorea.com/users/379418/ articles/495632-value-of-influenza-vaccines-in-cancer-patients-during-the-coronaviruscovid-19-pandemic

\section{Hosted file}

Tables.pdf available at https://authorea.com/users/379418/articles/495632-value-ofinfluenza-vaccines-in-cancer-patients-during-the-coronavirus-covid-19-pandemic 